\title{
Anxiolytic and anti-depressant effect of Salvia spp. essential oil on rat model of Autism Spectrum Disorder
}

\author{
Samson Guenné, Geoffroy G. Ouedraogo, Radu Lefter, Daniel Timofte, \\ Harquin Simplice Foyet, Adama Hilou, Martin Kiendrebéogo
}

\begin{abstract}
Samson Guenné - Laboratory of Applied Biochemistry and Chemistry (LA.BIO.C.A), University Joseph KI-ZERBO, 03 P.O. Box: 7021 Ouagadougou 03, Burkina Faso

Geoffroy G. Ouedraogo - Laboratoire de Toxicologie, Département Médecine, Pharmacopée Traditionnelles et Pharmacie, Institut de Recherche en Sciences de la Santé (MEPHATRAPH/IRSS/CNRST), 03 BP 7192 Ouagadougou, Burkina Faso

Radu Lefter - Center of Biomedical Research, Romanian Academy, Iasi, B dul Carol I, no 8, Romania

Daniel Timofte - Grigore T.Popa" University of Medicine and Pharmacy, 16, Universitatii Street, 700115, Iasi, Romania

Simplice Foyet - Department of Biological Sciences, Faculty of Science, University of Maroua, P.O. Box: 814, Maroua, Cameroon

Adama Hilou - Laboratory of Applied Biochemistry and Chemistry (LA.BIO.C.A), University Joseph KI-ZERBO, 03 P.O. Box: 7021 Ouagadougou 03, Burkina Faso

Martin Kiendrebéogo - Laboratory of Applied Biochemistry and Chemistry (LA.BIO.C.A), University Joseph KI-ZERBO, 03 P.O. Box: 7021 Ouagadougou 03, Burkina Faso
\end{abstract}

\begin{abstract}
Autism or Autism Spectrum Disorder (ASD) is a human psychiatric disorder characterized by abnormal social interaction and communication with restricted repetitive behaviors. This disorder is most often accompanied by anxiety and depression. Medicinal plants have an inexhaustible potential of bioactive molecules. Salvia spp. has an essential oil with psychotropic effects.

The aim of our study was to evaluate the anxiolytic and anti-depressant properties of Salvia spp. essential oil on rat model of ASD.

Social interaction (SIT), elevated plus maze (EPM) and forced swim (FS) tests methods were used respectively to assess autistic, anxiety and depression status of rats.

Rats with ASD spent less time in the cage containing the control rat or the new rat and more time in the empty cage in SIT compared to normal rats. Salvia spp. (3\%) essential oil has anxiolytic effect by decreasing the anxiety state created by valproic acid by increasing the
\end{abstract}


r.\% number and time spent in the open arms $(1.75 \pm 0.25 ; P=0.009, F=11.55)$ of the apparatus. Salvia essential oil had an antidepressant effect on VPA 500 rats with severe depression $(P=0.00078, F=16.233)$. This oil has significantly reduced the immobility time in forced swims. This study confirmed once again the pharmacological effect of the essential oil of Salvia genus plants on the one hand and their psychotropic potential exploited in traditional medicine on the other.

KEYWORDS:

Autism, Anxiety, Depression, Salvia spp..

\section{INTRODUCTION}

Anxiety is a psychological and physiological state that, in presence or absence of psychological stress, creates overwhelming feelings of fear and worry. Anxiety affects cognition and behavior $(1,2)$. Depression from Latin word deprimere is a mental disorder that can lead to a sense of incapacity, deep sadness, lack of a taste for life. This psychiatric disorder affects both men and women and has a wide variety of causes (3). These two disorders occur in individuals with ASD. Autism is manifested by human developmental disorders characterized by abnormal social interaction and communication with restricted repetitive behaviors. The serotonin system disturb is involved in the development of this pathology also, women exposure to valproic acid during early pregnancy $(4,5)$. The imbalance of serotonin or 5-hydroxytryptamine (5-HT) production is involved in psychiatric disorders and is observed during depression or anxiety. Autism, like all other neuropsychiatric disorders, does not have total treatments but only some of their symptoms are treated.

To better understand of these neuropsychiatric disorders, their animal models were created. Thus, for autism (ASD), valproic acid is early used during animal's pregnancy (6).

Since ancient times, medicinal plants have been medical basis for many people. This attachment to medicinal plants is still relevant today because they possess an inexhaustible source of bioactive molecules.

In this way of exploring medicinal plants for depression and anxiety created by the state of ASD treatment, we are interested in some plants from Lamiaceae family. Traditionally, also in the bibliography many plants of Salvia

spp. genus have been used for their psychotropic properties such as Salvia libanotica (Boiss and Gaill), Salvia lavendulaefolia Vahl, Salvia divinorum (Epling and Játiva M), Salvia multicaulis Vahl, Salvia cyanescens Boiss. (7, 8, 9, 10).

For these plants of Salvia genus, it is the essential oils that are generally used in traditional medicine for their psychotropic effects. Thus, our study aimed to evaluate the anxiolytic and anti-depression power of essential oils from Salvia spp. plants using rats with ASD.

Previous experimental or clinical studies using extracts of some Salvia genus plants have proven their anxiolytic effects through various methods (11).

\section{MATERIALS AND METHODS}

\subsection{Plant material and essential oil extraction}

Salvia spp. aerial parts were collected and dried away from sunlight, pulverized and weighed.

Essential oils of the dried powder of Salvia spp. were extracted by hydro-distillation with water vapor according to the method described by the 7th edition of European Pharmacopoeia using a Neo Clevenger type apparatus.

The volume of the essential oil was measured and ranked for $100 \mathrm{~g}$ dry plant material.

\subsection{Animals}

Thirty female and male Wistar rats weighing respectively $238.40 \pm 18.70 \mathrm{~g}$ and $310 \pm$ $48.60 \mathrm{~g}$ at the start of the experiment were used. The animals were housed in a temperature and light-controlled room $\left(22^{\circ} \mathrm{C}\right.$, 
a $12 \mathrm{~h}$ cycle starting at 08:00 h) and were fed and allowed to drink water ad libitum. All behavioral evaluations were performed between $9 \mathrm{~h}$ and $16 \mathrm{~h}$, respecting the current legislation for animal studies and indications of the local comities.

\subsection{Chemicals}

To carry out our research, we used valproic acid purchased from Sigma Aldrich Chemie (Steinheim, Germany).

\subsection{Experimental design}

Rats were divided into seven (7) groups (six animals per group) for the experiment performed: (1) control group (0.9\% $\mathrm{NaCl}),(2)$ VPA $500 \mathrm{mg} / \mathrm{kg}$ treated group, (3) VPA 300 $\mathrm{mg} / \mathrm{kg}$ treated group, (4) VPA $500 \mathrm{mg} / \mathrm{kg}+$ Salvia spp. volatile oil $1 \%$ group, (5) VPA $500 \mathrm{mg} / \mathrm{kg}+$ Salvia spp. volatile oil $3 \%$ treated group, (6) VPA $300 \mathrm{mg} / \mathrm{kg}+$ Salvia spp. volatile oil $1 \%$ treated group, and (7) VPA $300 \mathrm{mg} / \mathrm{kg}+$ Salvia spp. volatile oil $3 \%$ treated group. Inhalation method was used 60 min per day during 21 successive days for Salvia spp. volatile oil treated groups.

\section{5. EXPERIMENTS TRAINING}

\subsubsection{Social interaction test (SIT)}

The social interaction test assesses rat sociability and social novelty. The apparatus consisted of three rectangular compartments 19 x $45 \mathrm{~cm}$ connected by two doors. The two outer boxes had two boxes. After Salvia spp. essential oil exposition, the test involved two steps. In the first step, one of the external box contained a rat and one was empty and the tested rat was placed in the middle box. The tested rat could freely explored the two external boxes. In the second step, the 2 external boxes contained the rats and the same test rat was placed in the middle box and ultimately it freely explored the two outer boxes once again (12). The parameters evaluated were:

1. The number of entries in each outer compartment

2. The time spent in each outer compartment

3 . The number of contacts with another rat or with the empty cage
4. The contact time with another rat or the empty cage

\subsubsection{Elevated plus-maze task}

Behavior in the elevated plus-maze (EPM) is also utilized to assess exploration, anxiety, and motor behavior. The EPM consisted of four arms, $49 \mathrm{~cm}$ long and $10 \mathrm{~cm}$ wide, elevated $50 \mathrm{~cm}$ above the ground. Two arms were enclosed by walls $30 \mathrm{~cm}$ high and the other two arms were exposed. 1h after Salvia spp. essential oil exposition, rats were placed at the juncture of the open and closed arms and the amount of time spent on the open arms was recorded during a $5 \mathrm{~min}$ test, as previously described (13). After each assay, the maze was carefully cleaned with a wet tissue. The time spent on the open arms is an index of anxiety.

\subsubsection{Forced swimming test (FST)}

The antidepressant effects of Salvia spp. essential oil on rats were assessed, using the method described by Foyet (13) with some modifications. Firstly, rats were individually placed into cylindrical recipients (diameter 30 $\mathrm{cm}$, height $59 \mathrm{~cm}$ ) containing $25 \mathrm{~cm}$ of water at $24 \pm 1{ }^{\circ} \mathrm{C}$ during $2 \mathrm{~min}$ of training. After this session, the test was performed in a $6 \mathrm{~min}$ swim session. $1 \mathrm{~h}$ before the training, the rats had been exposed to Salvia spp. essential oil. During the test session, the following behavioral responses were recorded: (1) immobility (time spent floating with the minimal movements to keep the head above the water) and (2) swimming (time spent with active swimming movements).

\section{DATA ANALYSIS}

All results were expressed as mean \pm standard error of the mean (S.E.M). Behavioral activities of rats were statistically analyzed with analysis of variance (one-way ANOVA). Tukey's test was used to determine level of significance of all results obtained on XLSTAT 7.1. Results were regarded as significant at $\mathrm{p}<0.05$. 


\section{RESULTS}

4.1. Rats with ASD social behavior

Valproic acid had an impact on treated rat pups according to their behavioral contact with other control rats. Three doses of VPA were used $(150,300$ and $500 \mathrm{mg} / \mathrm{kg}$ of body weight). Rats from VPA treated rats spent more time and had more contacts in empty box Figure 1 and 2. Each figure consists of four graphs ( $a, b, c$ and $d)$.
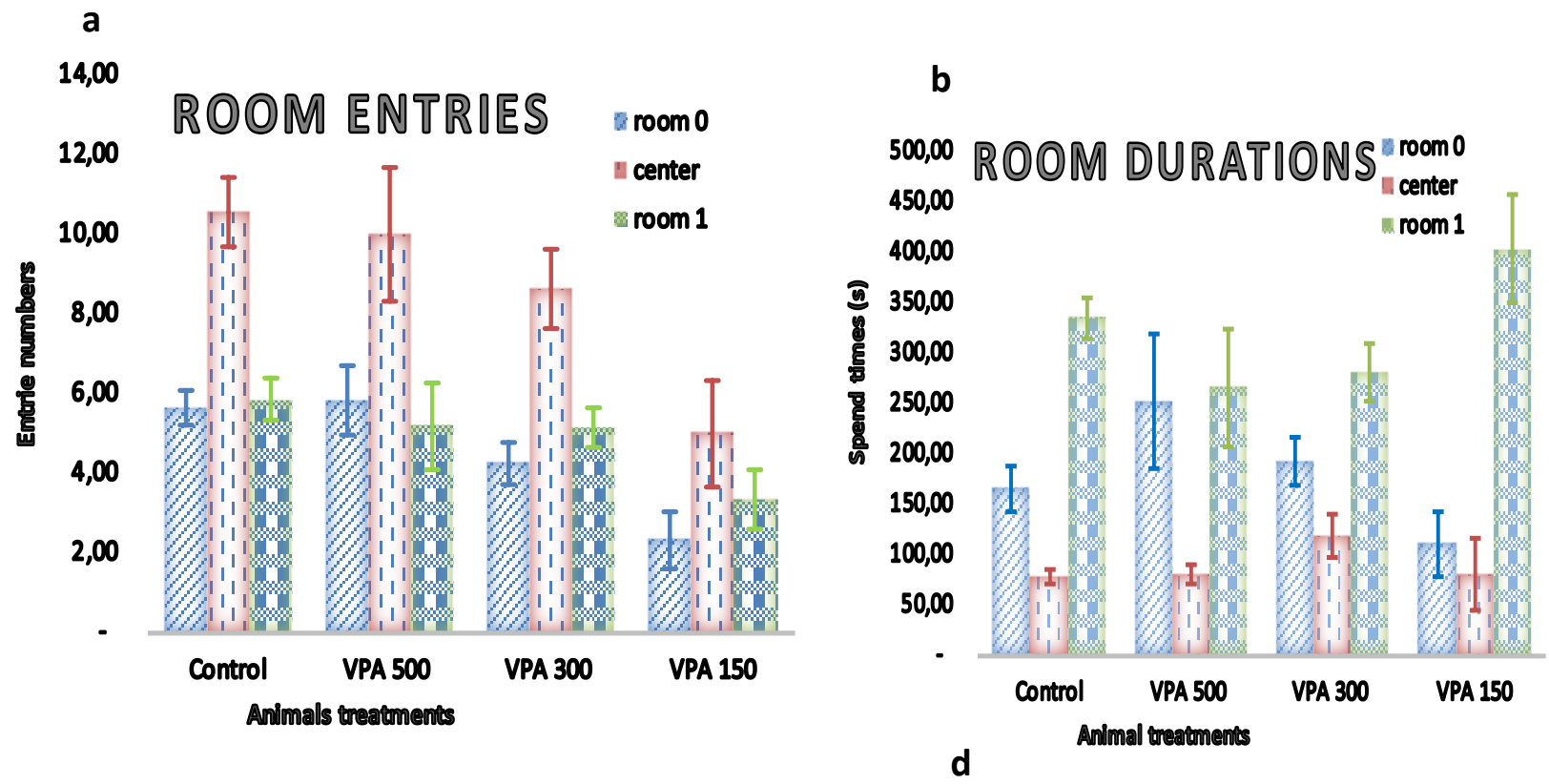

C
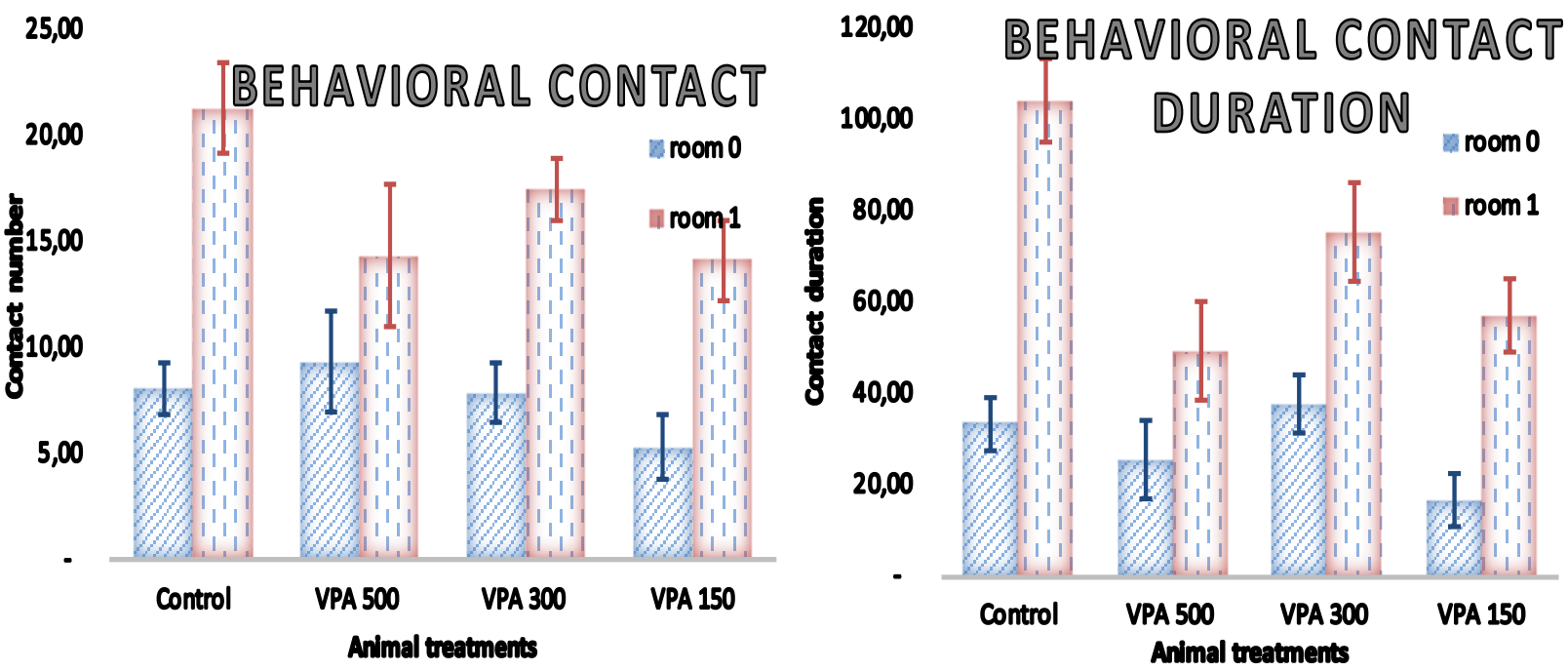

Figure 1: Valproic acid impact on rat social interaction

According to Figures 1 (c and d), tested rats most likely had an ASD because they had little contact and spent less time with the control rat (Box 1) $(14,15)$. 


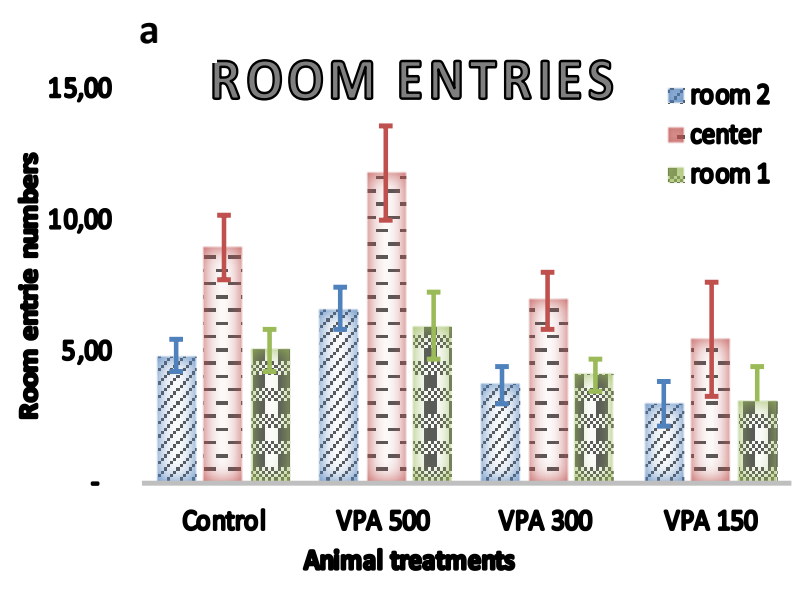

C

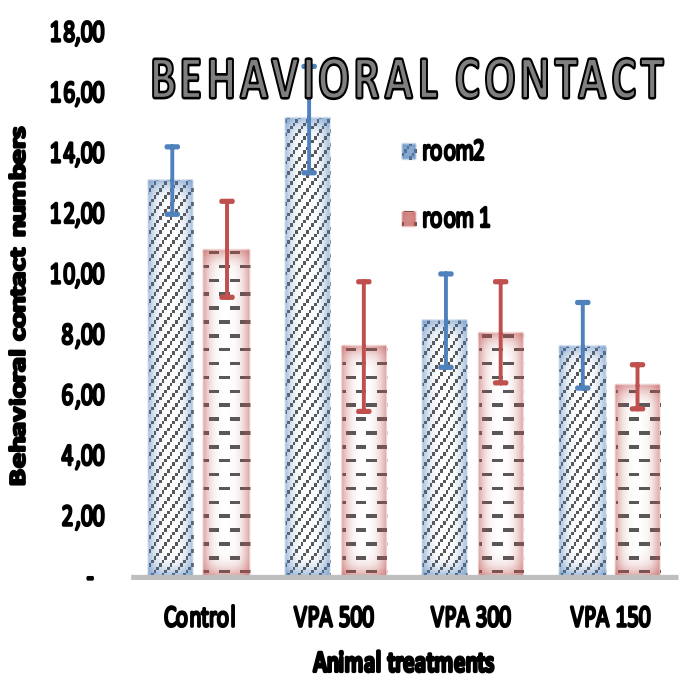

b

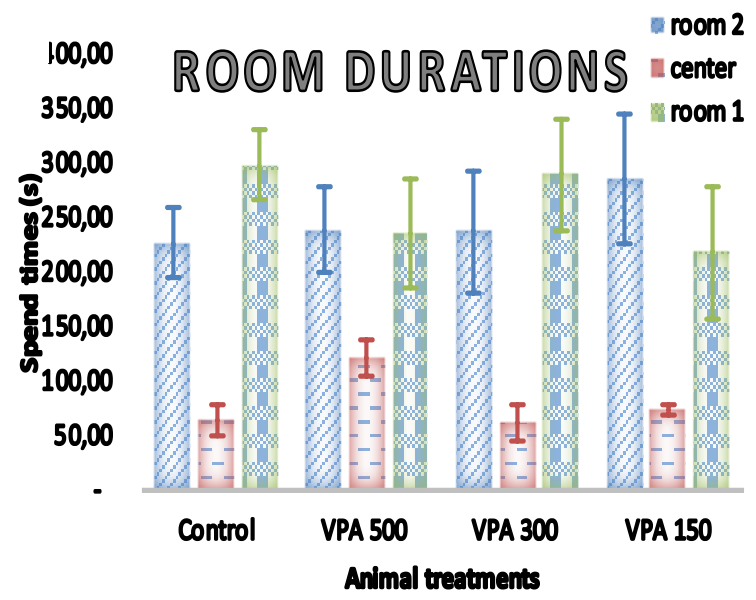

d

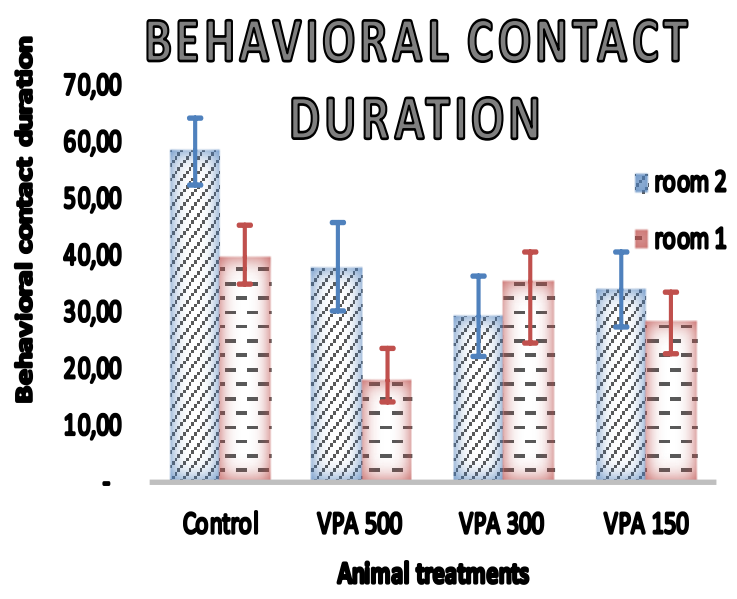

Figure 2: Valproic acid impact on rat novelty behavioral contact

Figure 2 (d) supports the fact that tested rats have ASD. However, these rats remained the least in contact with the new rat (box 2) introduced into the apparatus $(15,16)$.

\subsection{Anxiety in elevated plus maze}

The entries and duration in the open arms gave a state of the rat's anxiety. The reduction of entry number and the spent time in these arms indicates that animal is more anxious. Thus, valproic acid $500 \mathrm{mg} / \mathrm{kg}$ of body weight $(\mathrm{P}=0.027 ; \mathrm{F}=5.73)$ increased rat's anxiety state level compared to the control group. The essential oil of Salvia spp. 3\% (P $=0.009, \mathrm{~F}=11.55$ ) had significantly an antianxiety effect on rat treated with $500 \mathrm{mg} / \mathrm{kg}$ bw of VPA (Figure $3 a$ and $b$ ). 


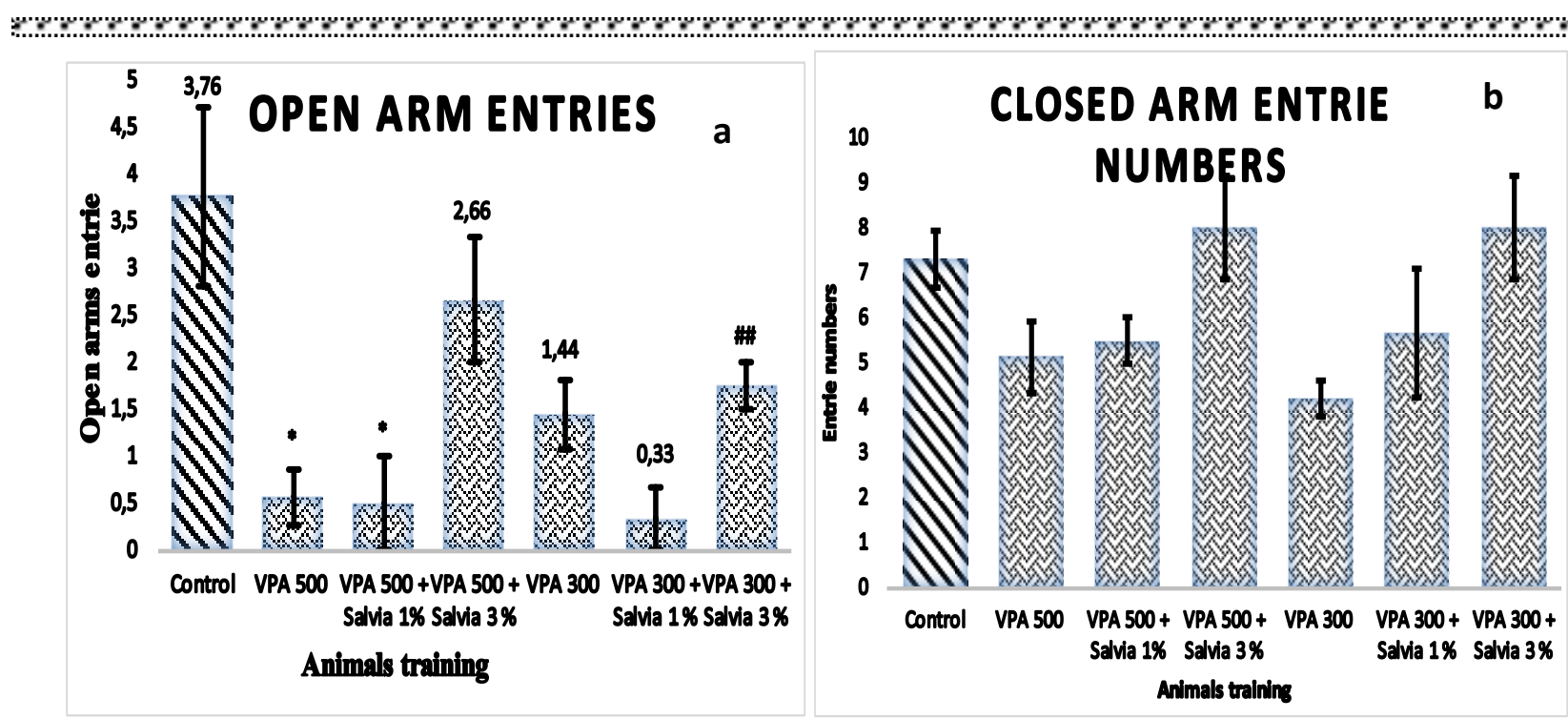

C

d

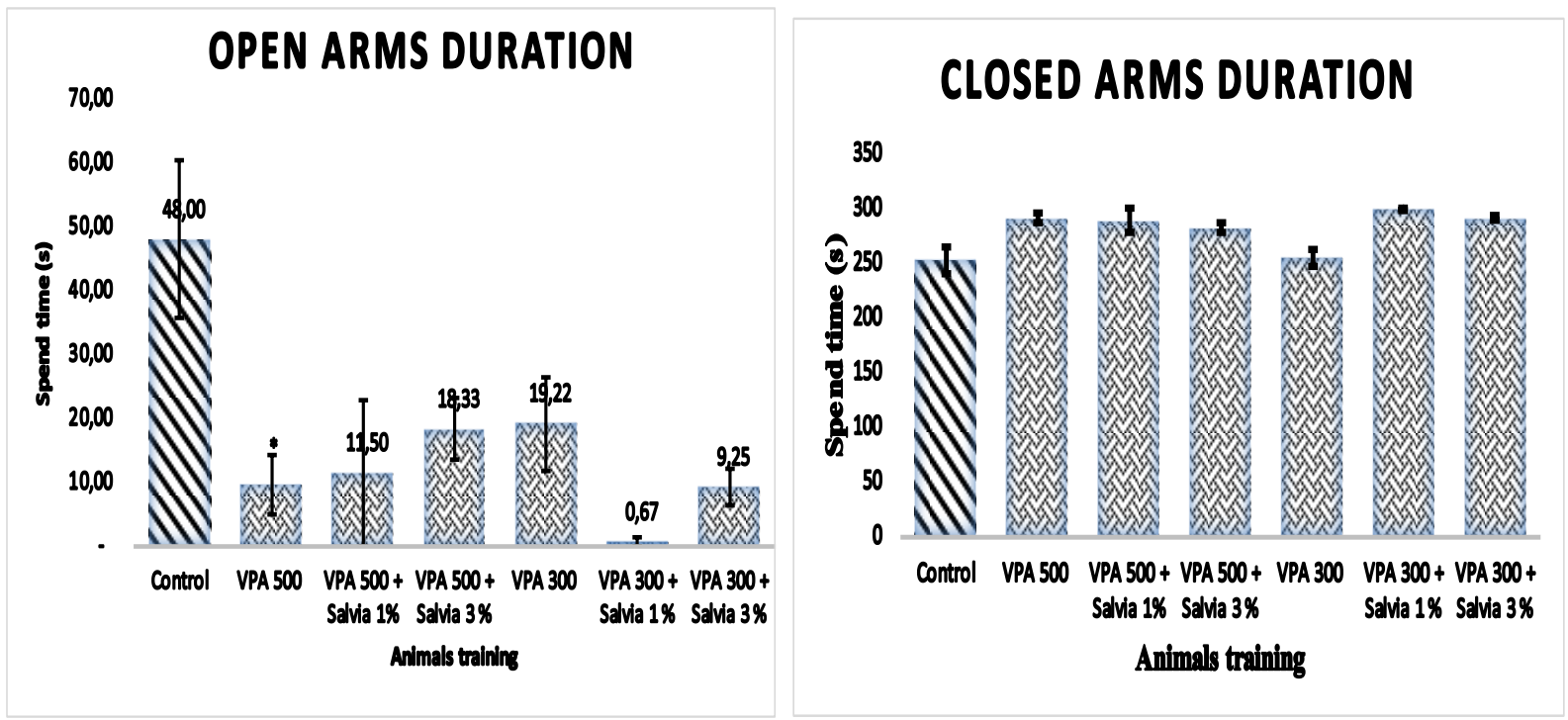

Figure 3: Salvia spp. essential oil effect in elevated plus maze open arms entries The values are mean \pm S.E.M. ( $n=6$ per test). ${ }^{*} \mathrm{p}<0.05$ vs. control; ${ }^{*}{ }^{*} \mathrm{p}<0.01$ vs. Control; \#\# $\mathrm{p}<$ 0.01 vs. VPA 300.

The entrance and the spent time in the closed arms of rodents showed no significant differences between control and treated groups (Figure $3 \mathrm{a}$ and $\mathrm{b}$ ).
However, rats' entries into the open arms and their stretching numbers showed that Salvia spp. essential oil pharmacological treatment decreased rats' mobility (Figure $3 \mathrm{c}$ and Figure 4). 

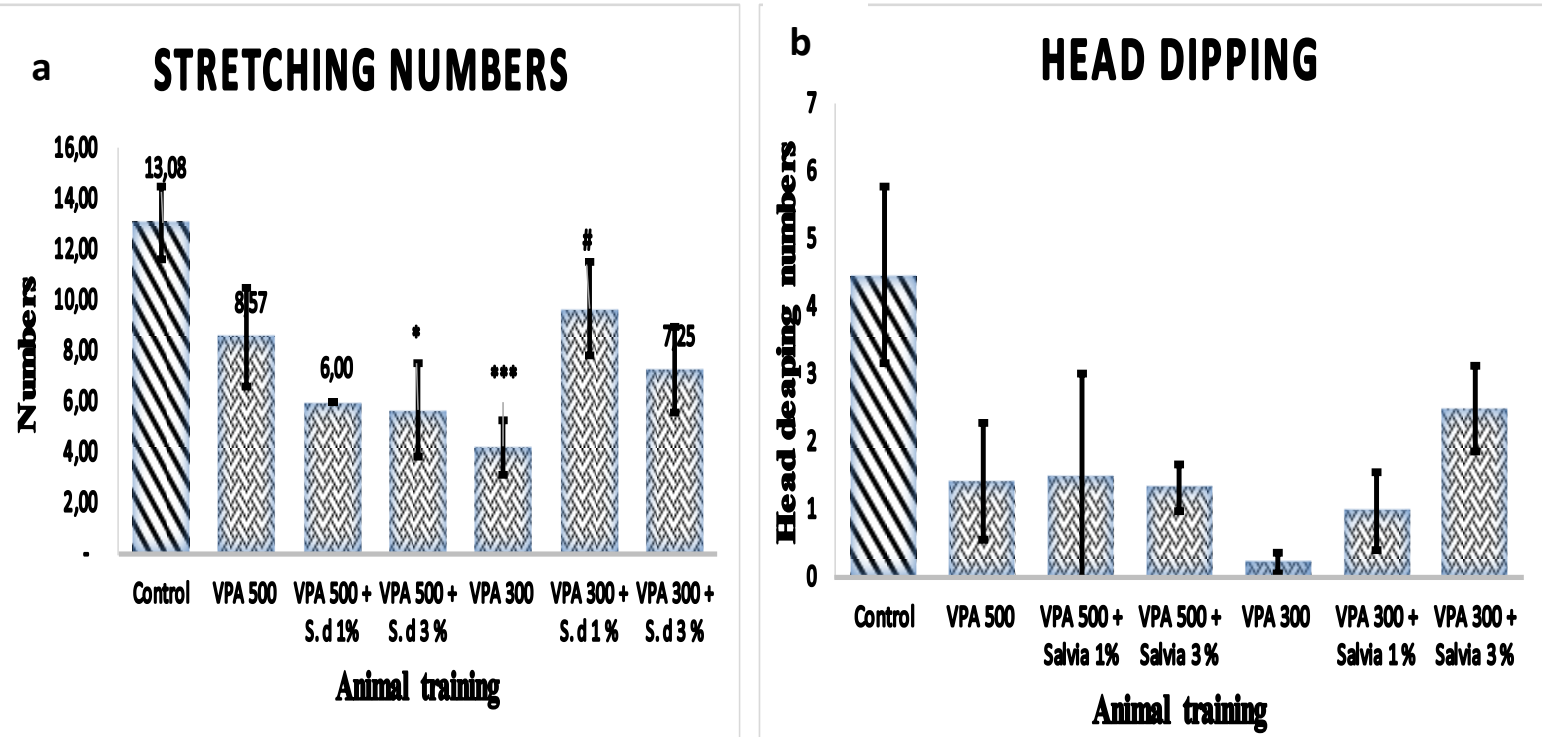

Figure 4: Salvia spp. essential oil effect on rodent stretching and head dipping in elevated plusmaze

The values are mean \pm S.E.M. ( $n=6$ per test). ${ }^{*} \mathrm{p}<0.05$ vs. control; $* * p<0.01$ vs. Control; $* * * \mathrm{p}<0.001$ vs. Control; \# $\mathrm{p}<0.05$ vs. VPA 300.

4.3 Anti-depressant capacity of Salvia spp. essential oil in forced swim

Valproic acid 300 and $500 \mathrm{mg} / \mathrm{kg}$ of body weight had a significant influence on rat's mobilities by increasing immobility time while decreasing the mobility period (figure 5 a and b). Salvia spp. 3\% significantly decreased the depression state created by VPA $500 \mathrm{mg} / \mathrm{kg}$.

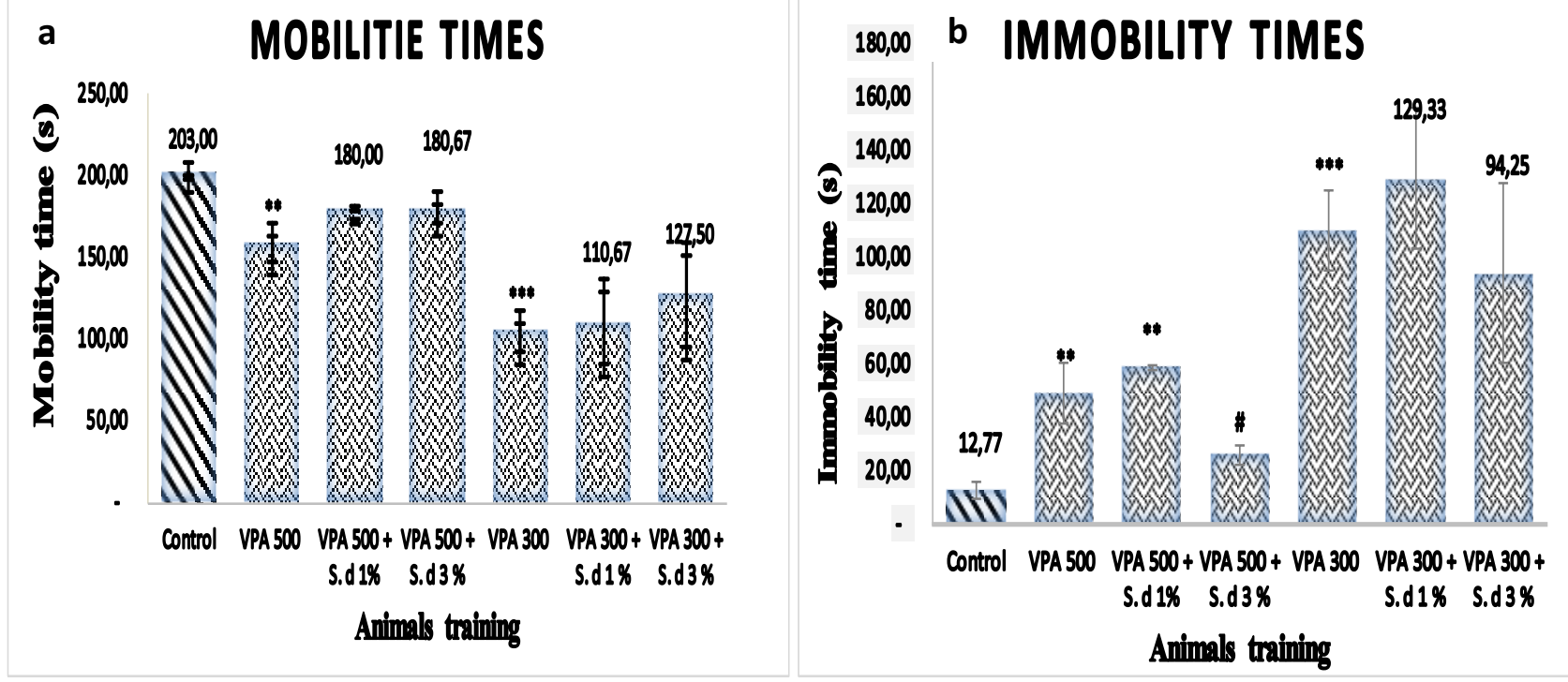

Figure 5: Salvia spp. essential oil effect on rodent in Forced swimming test

The values are mean \pm S.E.M. ( $n=6$ per test). $* \mathrm{p}<0.05$ vs. control; $* * p<0.01$ vs. Control; $* * * \mathrm{p}<0.001$ vs. Control; \# $\mathrm{p}<0.05$ vs. VPA 500. 


\section{DISCUSSION}

Autism or autism spectrum disorder (ASD) is a human neuropsychiatric disorder that manifests itself through social and communication difficulties with stereotypical and conservative behaviors. This disorder is associated to disruption of certain chromosomal genes already involved in mental delay $(17,18,19)$.

Oxytocin, a polypeptide of nine amino acids (HOOC- Cys- Tyr- Ile- Gln- Asn- CysPro- Leu- $\mathrm{Gly}-\mathrm{NH}_{2}$ ), is widely used to treat shyness, lack of self-confidence (behavioral disorders) in people with ASD.

Anxiety and depression are neuropsychiatric disorders that quite often disrupt the lives of people living with ASD $(20,21)$.

Nowadays, in modern medicine, there are drugs available to treat symptoms of these psychiatric disorders, but they are not easily accessible to low-income populations. Thus, medicinal plants have always been and remain the main medical source for these populations. It should be noted that medicinal plants have an inexhaustible potential for bioactive molecules.

In this way, several plants from Salvia genus are used in traditional medicine. Their richness in psychotropic compounds makes them mainly used for these mental disorders. It is the case with Salvia sclarea, Salvia divinorum, Salvia miltiorrhiza. (22, 23, 24).
The essential oils from some Salvia genus plants are well known for their psychotropic effects (25). During our research, the essential oil of Salvia spp. had an antidepressant and anxiolytic effect on the rat model of autism. Compounds from Salvia essential oil would act as one or more of these classes of antidepressants by inhibiting monoamine oxidase (MAOI) or tricyclic antidepressant (TCA) or tetracyclic antidepressant or by selectively inhibiting serotonin reuptake (SSRI) or by inhibiting serotonin and noradrenaline reuptake (SNRI) (26). This was achieved by trying to restore the neuropsychiatric disorder created by valproic acid during the first weeks of rat gestation. Some of these antidepressants have also anxiolytic properties, as do as GABA agonists, benzodiazepines, nonbenzodiazepines, barbiturates, carbamates, antihistamines and neuroleptics. The molecules of this essential oil would act using one of these action modes.

This study once again confirms psychotropic properties of species from Salvia spp. genus used in traditional rites and medicine $(27,28)$. Previous studies had reported on present compounds in Salvia genus plants essential oils $(29,30)$. These molecules would act as agonists or antagonists on specific receptors in the nervous system. This essential oil has its reason to be traditionally used as a psychotropic through its anxiolytic and antidepression properties.

\section{CONCLUSION}

Plants of Salvia genus are plants known for their plethora of essential oils and in alkaloids. These molecules are known to have actions on the central nervous system.

The essential oil of plants from Salvia genus has been used in the sense to treat anxiety and depression status present in autism animal model.

Valproic acid was used in the early weeks of rat gestation to create pups with autism spectrum disorder. Specific tests were used to distinguish rats with this neuropsychiatric tare.

Exposure of rats with ASD to Salvia spp. essential oil for a few weeks showed a mild anxiolytic and high anti-depression effect using EPM and FS tests, respectively.

This study confirms once again the pharmacological effect of the essential oil of Salvia genus plants on the one hand and their psychotropic potential exploited in traditional medicine on the other. 


\section{ACKNOWLEDGEMENTS AND DISCLOSURES}

The authors like to thank Prof. L.H. from Al.I. Cuza University for kindly providing the Salvia sp. extract. The authors are stating that there is no conflict of interest to disclose, except for Radu Lefter which is supported by a Young Teams grant offered by UEFISCDI Romania, no. PN-III-P11.1-TE-2016- 1210, contract no. 58 from 02/05/2018.

\section{REFERENCES}

1. Taylor S, Koch WJ, McNally RJ. How does anxiety sensitivity vary across the anxiety disorders? J Anxiety Disord [Internet]. 1992 Jul 1 [cited 2019 Nov 8];6(3):249-59. Available from: https://www.sciencedirect.com/science/article/pii/0887618592900378

2. Murray B Stein, Stein DJ. Social anxiety disorder. Lancet [Internet]. 2008 Mar 29 [cited 2019 Nov 8];371(9618):1-11. Available from: https://www.sciencedirect.com/science/article/pii/S0140673608604882

3. North TC, McCullagh P, Vu TZ. Effects of Exercise on Depression: Exercise and Sport Sciences Reviews. Exerc Sport Sci Rev [Internet]. 1990 [cited 2019 Nov 8];18(1):379-416. Available from: https://journals.lww.com/acsmessr/Citation/1990/01000/Effect_of_Exercise_on_Depression.16.aspx

4. Lenoir P, Bodier C, Desombre H, Malvy J, Abert B, Ould Taleb M, et al. Sur la prévalence de l'autisme et des troubles envahissants du développement (TED). Encephale [Internet]. 2009 Feb 1 [cited 2019 Nov 13];35(1):36-42. Available from: https://www.sciencedirect.com/science/article/abs/pii/S0013700608001565

5. Kinast K, Peeters D, Kolk SM, Schubert D, Homberg JR. Genetic and pharmacological manipulations of the serotonergic system in early life: Neurodevelopmental underpinnings of autism-related behaviour running title: Neurodevelopmental serotonin and behaviour. Frontiers in Cellular Neuroscience. 2013.

6. Lefter R, Cojocaru D, Ciobica A, Paulet IM, Serban IL, Anton E. Aspects of animal models for major neuropsychiatric disorders. Arch Biol Sci. 2014;66(3):1105-15.

7. Gali-Muhtasib H, Hilan C, Khater C. Traditional uses of Salvia libanotica (East Mediterranean sage) and the effects of its essential oils. J Ethnopharmacol [Internet]. 2000 Aug 1 [cited 2019 Nov 15];71(3):513-20. Available from: https://www.sciencedirect.com/science/article/pii/S0378874199001907

8. Adams M, Gmünder F, Hamburger M. Plants traditionally used in age related brain disorders-A survey of ethnobotanical literature [Internet]. Vol. 113, Journal of Ethnopharmacology. Elsevier; 2007 [cited 2019 Nov 15]. p. 363-81. Available from: https://www.sciencedirect.com/science/article/pii/S037887410700356X

9. Orhan I, Kartal M, Naz Q, Ejaz A, Yilmaz G, Kan Y, et al. Antioxidant and anticholinesterase evaluation of selected Turkish Salvia species. Food Chem [Internet]. 2007 Jan 1 [cited 2019 Nov 6];103(4):1247-54. Available from: https://www.sciencedirect.com/science/article/pii/S0308814606008168

10. Ahern NR, Greenberg CS. Psychoactive herb use and youth: A closer look at salvia divinorum. J Psychosoc Nurs Ment Health Serv. 2011;49(8):16-9.

11. Sarris J, McIntyre E, Camfield DA. Plant-based medicines for anxiety disorders, part 2: A review of clinical studies with supporting preclinical evidence. Vol. 27, CNS Drugs. Springer International Publishing; 2013. p. 301-19.

12. Kaidanovich-Beilin O, Lipina T, Vukobradovic I, Roder J, Woodgett JR. Assessment of social interaction behaviors. Journal of Visualized Experiments. Journal of Visualized Experiments; 2010.

13. Foyet HS, Hritcu L, Ciobica A, Stefan M, Kamtchouing P, Cojocaru D. Methanolic extract of Hibiscus asper leaves improves spatial memory deficits in the 6-hydroxydopamine-lesion rodent model of Parkinson's disease. J Ethnopharmacol [Internet]. 2011 Jan 27 [cited 2019 Oct 24];133(2):773-9. Available from: https://www.sciencedirect.com/science/article/pii/S037887411000783X

14. Dufour-Rainfray D, Vourc'h P, Le Guisquet AM, Garreau L, Ternant D, Bodard S, et al. Behavior and serotonergic disorders in rats exposed prenatally to valproate: A model for autism. Neurosci Lett [Internet]. 2010 Feb 5 [cited 2019 Nov 18];470(1):55-9. Available from: https://www.sciencedirect.com/ science/article/pii/ S030439400901636X

15. Lin HC, Gean PW, Wang CC, Chan YH, Chen PS. The Amygdala Excitatory/Inhibitory Balance in a ValproateInduced Rat Autism Model. Chang AYW, editor. PLoS One [Internet]. 2013 Jan 29 [cited 2019 Nov 18];8(1):e55248. Available from: https://dx.plos.org/10.1371/journal.pone.0055248

16. Roullet FI, Crawley JN. Mouse models of autism: Testing hypotheses about molecular mechanisms. Curr Top Behav Neurosci. 2011;7(1):187-212.

17. Marshall CR, Noor A, Vincent JB, Lionel AC, Feuk L, Skaug J, et al. Structural Variation of Chromosomes in Autism Spectrum Disorder. Am J Hum Genet [Internet]. 2008 Feb 8 [cited 2019 Nov 25];82(2):477-88. Available from: https://www.sciencedirect.com/science/article/pii/S0002929707000353\#fig2

18. Toro R, Konyukh M, Delorme R, Leblond C, Chaste P, Fauchereau F, et al. Key role for gene dosage and synaptic homeostasis in autism spectrum disorders [Internet]. Vol. 26, Trends in Genetics. Elsevier Current Trends; 2010 [cited 2019 Nov 25]. p. 363-72. Available from: https://www.sciencedirect.com/science/article/pii/S0168952510001071 
19. Sato D, Lionel AC, Leblond CS, Prasad A, Pinto D, Walker S, et al. SHANK1 deletions in males with autism spectrum disorder. Am J Hum Genet [Internet]. 2012 May 4 [cited 2019 Nov 25];90(5):879-87. Available from: https://www.sciencedirect.com/science/article/pii/S0002929712001619

20. Muskett A, Capriola-Hall NN, Radtke SR, Factor R, Scarpa A. Repetitive behaviors in Autism Spectrum Disorder: Associations with depression and anxiety symptoms. Res Autism Spectr Disord [Internet]. 2019 Dec 1 [cited 2019 Nov 25];68:101449. Available from: https://www.sciencedirect.com/science/article/pii/S1750946719301370

21. Murphy J, Prentice F, Walsh R, Catmur C, Bird G. Autism and transgender identity: Implications for depression and anxiety. Res Autism Spectr Disord [Internet]. 2020 Jan 1 [cited 2019 Nov 25];69:101466. Available from: https://www.sciencedirect.com/science/article/pii/S1750946719301540

22. Seol GH, Shim HS, Kim PJ, Moon HK, Lee KH, Shim I, et al. Antidepressant-like effect of Salvia sclarea is explained by modulation of dopamine activities in rats. J Ethnopharmacol [Internet]. 2010 Jul 6 [cited 2019 Nov 25];130(1):187-90. Available from: https://www.sciencedirect.com/science/article/pii/S0378874110002667

23. Listos J, Merska A, Fidecka S. Pharmacological activity of Salvinorin A, the major component of Salvia divinorum [Internet]. Vol. 63, Pharmacological Reports. Elsevier; 2011 [cited 2019 Nov 25]. p. 1305-9. Available from: https://www.sciencedirect.com/science/article/pii/S1734114011706946

24. Chen Y, Hu J, Zhang Y, Han C, Li J. Anti-Alzheimer's disease effect of essential oil from aerial parts of Salvia miltiorrhiza Bge. Int J Clin Exp Med [Internet]. 2018 [cited 2019 Nov 25];11(2):641-52. Available from: www.ijcem.com/

25. Perry NSL, Bollen C, Perry EK, Ballard C. Salvia for dementia therapy: Review of pharmacological activity and pilot tolerability clinical trial [Internet]. Vol. 75, Pharmacology Biochemistry and Behavior. Elsevier; 2003 [cited 2019 Nov 27]. p. 651-9. Available from: https://www.sciencedirect.com/science/article/pii/S0091305703001084

26. David DJ, Gourion D. Antidépresseurs et tolérance: déterminants et prise en charge des principaux effets indésirables. Encephale [Internet]. 2016 Dec 1 [cited 2019 Nov 27];42(6):553-61. Available from: https://www.sciencedirect.com/science/article/pii/S0013700616301269

27. Valdés LJ, Díaz J, Paul AG. Ethnopharmacology of ska María Pastora (Salvia divinorum, Epling AND Játiva-M.). J Ethnopharmacol. 1983;7(3):287-312.

28. Giroud C, Felber F, Augsburger M, Horisberger B, Rivier L, Mangin P. Salvia divinorum: An hallucinogenic mint which might become a new recreational drug in Switzerland. Forensic Sci Int. 2000;112(2-3):143-50.

29. Russo A, Formisano C, Rigano D, Cardile V, Arnold NA, Senatore F. Comparative phytochemical profile and antiproliferative activity on human melanoma cells of essential oils of three lebanese Salvia species. Ind Crops Prod [Internet]. 2016 May 1 [cited 2019 Dec 3];83:492-9. Available from: https://www.sciencedirect.com/science/article/pii/S0926669015306695

30. Temel HE, Demirci B, Demirci F, Celep F, Kahraman A, Doğan M, et al. Chemical characterization and anticholinesterase effects of essential oils derived from Salvia species. J Essent Oil Res. 2016 Jul 3;28(4):322-31.

\section{Correspondence}

Daniel Timofte,

MD, PhD, professor, "Grigore T.Popa” University of Medicine and Pharmacy, 16, Universitatii Street, 700115, Iasi, Romania, dantimofte@yahoo.com

Submission: 10 jan 2020

Acceptance: 03 mar 2020 